\title{
Los derechos e inclusión de las víctimas del conflicto armado vs. las obligaciones Estado colombiano
}

\section{The rights and inclusion of the victims of the armed conflict vs. the obligations of the Colombian State}

DOI: https://doi.org/10.17981/juridcuc.15.1.2019.13

Fecha de Recepción: 19/08/2019. Fecha de Aceptación: 02/09/2019

\author{
Berónica Narváez Mercado \\ Corporación Universitaria del Caribe (Colombia) \\ beronica.narvaez@cecar.edu.co
}
Namiko Matzumoto Benitez
Universidad Veracruzana (México)
presidencia@cedhveracruz.org.mx

\author{
Luz Elena Mira-Olano \\ Tecnológico de Antioquia I.U. (Colombia) \\ abogadaluzelenamirao@gmail.com
}

\section{Alejando Zúñiga-Bolívar \\ Corporación Universitaria de Colombia (Colombia) zunigabolivar.alejandro@gmail.com}

Para citar este artículo:

Narváez, B., Matzumoto, N., Mira-Olano y Zuñiga-Bolívar, A. (2019). Los derechos e inclusión de las víctimas del conflicto armado vs. las obligaciones Estado colombiano. JURÍDICAS CUC, 15(1). 321-352. DOI: http://dx.doi.org/10.17981/juridcuc.15.1.2019.13

Resumen

La interpretación dinámica de los Derechos Humanos implica adoptar una visión que difiere conceptualmente de la instituida desde el final de la segunda guerra mundial, época en la cual se avizoró su tutela jurídica, pero también su progresiva evolución. La dogmática moderna de los Derechos Humanos concibe un corpus juris de protección, determinando la abolición de categorías y jerarquías entre sí, que llevaban a una contradicción de la interrelación y la interdependencia instituido de ellos. El presente artículo acudió a la hermenéutica que conlleva necesariamente una interpretación de los fenómenos estudiados plasmando el desarrollo jurisprudencial de la Corte Interamericana de Derechos Humanos y los distintos pronunciamientos del Sistema Regional, a partir de los cuales, se logró determinar el alcance de las obligaciones estatales de investigar, juzgar y sancionar a los perpetradores de vulneraciones a los Derechos Humanos en el marco de los procesos de paz.

Palabras clave: Paz; Derechos; Inclusión; Víctimas y Conflicto Armado.
Abstract

The dynamic interpretation of human rights implies adopting a vision that differs conceptually from that instituted since the end of the Second World War, when its legal protection was envisioned, but also its progressive evolution. The modern dogma of human rights conceives a corpus juris of protection, determining the abolition of categories and hierarchies among them, which led to a contradiction of the interrelation and the interdependence instituted by them. This article turned to hermeneutics, which necessarily entails an interpretation of the phenomena studied, embodying the jurisprudential development of the Inter-American Court of Human Rights and the different pronouncements of the Regional System, from which it was possible to determine the scope of state obligations to investigate, judge and punish the perpetrators of human rights violations within the framework of peace processes.

Keywords: Peace; Rights; Inclusion; Victims and Armed Conflict 


\section{INTRODUCCIÓN}

La lucha contra la impunidad de las graves violaciones a los Derechos humanos, se ha convertido en un asunto de primer orden en el Derecho Internacional, concatenado con la obligación de investigar, juzgar y sancionar, de acuerdo a los estándares de la debida diligencia. No obstante, se han generado algunas dudas en torno al alcance de éstos cuando el Estado busca restablecer derechos en el marco de un proceso de transición hacia la paz. Es en éste contexto donde el Sistema Interamericano, a través de sus pronunciamientos ha resuelto algunas cuestiones relativas a la adopción de alternativas jurídicas y convencionales para dar fin a conflictos armados, sin desconocer los parámetros internacionales, que puedan llevar a una declaración de responsabilidad internacional de los Estados. Lo anterior tiene gran relevancia cuando se presenta una clara tensión con los derechos a la verdad, justicia y reparación, cuya titularidad reposa en cabeza de las víctimas del conflicto armado. Por lo cual se hace imperiosamente necesario construir una alternativa jurídica que permita la articulación entre los mecanismos de una justicia de transición, las disposiciones extrajudiciales y las penas alternativas en aras de alcanzar la Paz.

Ahora bien, en el proceso del restablecimiento de derechos a las víctimas y juzgamiento a los responsables de la comisión de conductas punibles, los Estados han implementado figuras como la amnistía y el indulto para finiquitar los conflictos suscitados en su territorios, formas jurídicas que no eran sometidas a cuestionamiento alguno en la esfera internacional, sin embargo, a partir de la sentencia del caso Barrios Altos vs. Perú (Corte Interamericana de Derechos Humanos-CIDH, 2001), se empiezan a cuestionar tajantemente, debido a la problemática que se suscitaban ante las demandas de justicia al interior de los Estados y los parámetros para alcanzar una paz negociada sin generar fuentes de impunidad que originaría, no sólo la responsabilidad internacional del Estado desde los organismos de protección internacional de Derechos Humanos, sino una responsabilidad individual, desde la esfera del Derecho Penal Internacional. 
No obstante, en el año 2012, desde el Sistema Interamericano se emite un pronunciamiento donde deja en evidencia, que no existe en el derecho internacional positivo una norma a través de la cual se haya proscrito explícitamente todo tipo de amnistía (CIDH, 2012), además de indicar que si bien las amnistías pueden adoptarse como elemento determinante en la terminación de un conflicto armado no internacional, las mismas no son de aplicación absoluta en tratándose de delitos de lesa humanidad, y crímenes de guerra. Estos límites se encuentran en lo aludido a las "fuentes implícitamente relacionadas a la amnistía” (Freeman, 2009).

Es este contexto donde adquieren mayor relevancia los derechos de las víctimas, se empiezan a considerar interdependientes y es de esa manera como deben analizarse en la consecución de una paz duradera. Es así como el honorable Tribunal arguye que sólo la aplicación integrada de medidas en favor de las víctimas, respecto de la verdad, la justicia y la reparación, pueden ser determinantes en la obtención de resultados eficaces y acordes con el orden interamericano.

\section{Metodología}

En este caso de estudio se selecciona el paradigma interpretativo o paradigma cualitativo, el cual se centra en el estudio de los significados de las acciones humanas y de la vida social, según lo expuesto por Martínez (2012). Asimismo, desde el punto de vista de las fuentes de información que sirven de apoyo a este estudio, se enmarca dentro del tipo de estudio documental, según Arias (2006) quien define la investigación documental como “... aquella que se basa en la obtención y análisis de datos provenientes de materiales impresos u otros tipos de documentos" (p. 114).

De igual manera, por su contenido, esta investigación se enmarcó dentro de los estudios de tipo jurídico-dogmático. Según Estraño (2009):

Esta técnica jurídica dogmática reúne los más altos criterios de credibilidad, su originalidad se refleja en el enfoque, criterios, conceptualizaciones, reflexiones, además de ofrecer algunas conclusiones, recomendaciones, en forma de reflexiones finales. Es 
así que esta técnica se utiliza en revisiones criticas del estado del conocimiento sobre un problema jurídico, integrando, organizando y evaluando la información contenida en las fuentes del derecho, en estudios de derecho comparado para analizar semejanzas, diferencias y tendencias sobre características o problemas jurídicos en el contexto de realidades socioculturales, geográficas o históricas diversas, con fundamento en las fuentes del derecho o en estudios de investigación jurídica histórica.

Por otra parte, en la presente investigación, se emplea un diseño bibliográfico cuyos datos, según Sabino (1996) "se obtienen de fuentes secundarias" (p. 71), es decir, que han sido previamente obtenidos, procesados por otros investigadores. De igual modo, la técnica será la observación documental, de acuerdo con Balcázar, Gonzalez, Gurrola y Moysen (2015), que es "aquella que se emplea cuando las unidades de observación están constituidas por documentos" (p. 145), aun cuando se hace uso de la observación fáctica, por tratarse de hechos o fenómenos observables.

En lo que respecta a las técnicas de interpretación utilizadas para el análisis de los resultados de la investigación, se acudió a la hermenéutica que significa interpretar, como afirma Martínez (2012), como método utilizado en la investigación científica, pues esta "conlleva necesariamente a una interpretación de los fenómenos estudiados". (p. 89). De igual manera, se emplea la técnica del análisis de contenido, la cual según Ander-Egg (2014) "integra diversos recursos que permiten abordar los eventos de estudio, hechos, situaciones, textos, autores, video, cine, con el interés de profundizar en su comprensión" (p. 217).

\section{El Valor de la Paz}

Los Acuerdos de Paz en Colombia son un asunto de la mayor relevancia para la comunidad internacional, no sólo por su calado político-jurídico, sino por la trascendencia moral de, en definitiva, poner un punto final al conflicto armado que azotó este país por tantos años y que enfrentó a las Fuerzas Armadas del Gobierno Colombiano y a las Fuerzas Armadas Revolucionarias de Colombia (FARC). 
Las consecuencias de este conflicto, además de funestas, se encuentran registradas en diversos dispositivos. De entre éstos, uno de los más significativos ha sido la jurisprudencia de la Corte Interamericana de Derechos Humanos (CIDH), pues además de documentar y retratar la crudeza del conflicto a través de los testimonios de las personas involucradas, por medio de sus sentencias ha sido posible reparar algunos de los daños que el conflicto armado dejó tras de sí. Es por todos sabido que los conflictos armados dejan, a su paso, una estela de dolor. En efecto, el suscitado en Colombia provocó un sufrimiento y un daño generalizado a la población, que no tiene parangón en la historia de este país. Millones de colombianos y colombianas fueron víctimas de desplazamiento forzado; cientos de miles de víctimas perdieron la vida, decenas de miles los desaparecidos de toda índole y un amplio número de colectivos y poblaciones afectadas a lo largo y ancho del territorio; sin soslayar otras formas menos visibles pero no menos dolorosas de victimización, como la violencia sexual, las afectaciones psicológicas, o la simple convivencia con el miedo (República de Colombia. FARC-EP. Acuerdo Final, 2016), como lo contempla el Acuerdo Final para la terminación del Conflicto y la Construcción de una Paz Estable y Duradera. Por lo anterior, se hace relevante hacer alusión a la trascendencia jurídico-política de la Firma y posterior implementación de los Acuerdos de Paz y la manera en que influirán el desarrollo del derecho constitucional latinoamericano y el derecho internacional de los derechos humanos.

Como todos sabemos, el derecho internacional de los derechos humanos es una rama de la ciencia jurídica que actúa como vaso comunicante en los distintos órdenes jurídicos vigentes en América Latina. La disciplina jurídica que ha actuado como receptáculo de este desarrollo en sede doméstica ha sido el derecho constitucional (CIDH, 2010). La firma de los acuerdos de paz en Colombia han dado una lección al mundo, pues nos ha demostrado que alcanzar la paz no es una cuestión sujeta a opiniones, sino que es un imperativo de cualquier sociedad, incluso cuando sus consecuencias puedan parecer, prima facie, no deseables o hasta criticables. 
El valor de la paz es una premisa indispensable para la convivencia civil, pues en su ausencia es imposible para los seres humanos vivir en sociedad. Por ello, el reconocerla como el principio subyacente a los acuerdos entre el Gobierno y las FARC tiene una trascendencia superlativa, pues la paz representa el fundamento principal del contrato social y la razón misma del artificio jurídico e institucional, cuya finalidad es, precisamente, proteger y garantizar la vida de los asociados contra la ley del más fuerte que rige en los contextos de un conflicto armado.

Esta afirmación tiene asidero constitucional en el ordenamiento jurídico colombiano. En efecto, el artículo 22 de la norma suprema, reconoce a la paz como un derecho y como un deber de cumplimiento obligatorio.

Este precepto dota de sentido en buena medida no sólo a la negociación sino también las acciones del Estado colombiano para llevar a cabo una implementación de los acuerdos para alcanzar, finalmente, la pacificación de Colombia y el restablecimiento de los derechos de las víctimas.

\section{Sobre el Carácter Contra-mayoritario del}

Derecho Humano a la Paz, reconocido en el Artículo 22 de la Constitución Política de Colombia

El carácter contra-mayoritario de los derechos humanos significa, básicamente, que nadie, ni siquiera la mayoría más aplastante, puede disponer legítimamente de los derechos. Esta afirmación contrasta radicalmente con una idea muy difundida, pero también simplista de la democracia.

De acuerdo a esta reducida idea de la democracia, cualquier decisión puede ser legitimada, aun cuando sea moralmente aberrante, cuando existe consenso de la mayoría. A la luz de esta concepción, las decisiones políticas son legítimas cuando el pueblo, a través de sus representantes, decide sobre algún asunto de acuerdo con la regla de la mayoría. Así, las condiciones de legitimidad se sustentan en el quién -el pueblo- y el cómo -la regla de la mayoría-, sin tomar en consideración el contenido de la decisión. 
Según esta forma de ver el fenómeno democrático, se han legitimado aberrantes decisiones judiciales como los casos Dred Scott v. Sandford (SCOTUS, 1857) y Plessy v. Fergusson (SCOTUS, 1896) dignas solamente de ser olvidadas. El fundamento de esas sentencias fue la visión racista que permeaba en el pueblo de los Estados Unidos de América en el siglo XIX, respaldada por la mayoría de las personas. Estas decisiones privaron de la totalidad de sus derechos a las personas de origen afroamericano y, en el mejor de los casos, los menoscabaron de manera significativa. Los efectos de esas sentencias se sintieron hasta mediados del siglo XX, cuando la Corte Suprema de Estados dictó el histórico fallo de Brown v. Board of Education (SCOTUS, 1954) en el que declaró que la segregación racial era inconstitucional.

También, el consenso de las mayorías ha legitimado regímenes políticos los cuales, vencedores en elecciones libres, se convirtieron en aparatos sistemáticos de violaciones gravísimas a los derechos humanos, desapariciones forzadas, ejecuciones extrajudiciales, tortura y represión a los opositores políticos. En nuestro continente, un claro ejemplo de lo anterior fue la dictadura de Fujimori, quien venció al candidato Mario Vargas Llosa; pero la demostración más cruda fue el régimen hitleriano que acabó con la vida de millones de personas y cuyas consecuencias son ampliamente conocidas por todos nosotros.

Con lo anterior no se pretende dar a entender, que la democracia no tenga virtudes o carezca de sentido, sino simplemente que el consenso de las mayorías no puede ser invocado como fuente de legitimación de todas las decisiones políticas de un Estado Constitucional. En efecto, en un estado democrático y social de derecho, las decisiones políticas se adoptan por los representantes del pueblo, de acuerdo con la regla de la mayoría, pero también de acuerdo con los valores constitucionales y los derechos humanos que orientan toda la actuación del Estado y que le imponen límites y vínculos sustanciales, los cuales deben ser respetados bajo pena de invalidez (Ferrajoli, 2009). 
Así, las decisiones democráticas lo son, sí y sólo si, además de ser adoptadas por los representantes del pueblo mediante la regla de la mayoría, respetan los valores, principios y derechos consagrados en las constituciones.

Estas consideraciones orientan la interpretación de la Constitución de Colombia (art. 22, 1991), pues al ser la paz un derecho de cumplimiento obligatorio, el Estado tiene el deber inexcusable de hacerlo valer en la vida de las personas bajo su jurisdicción y ello transforma, a su vez, a la paz, entendida como valor constitucional, como un bien que no puede ser interpretado desde la visión de la mayoría.

La Corte Constitucional colombiana (Sentencia ST-008, 1992) ha sostenido que, derivado de la naturaleza de este derecho, para su eficacia se requiere del concurso de los más variados factores sociales, políticos, económicos e ideológicos que, recíprocamente se le pueden exigir sin que se haga realidad por su naturaleza concursal o solidaria.

Este derecho fundamental además, conmina a las autoridades a organizar el aparato gubernamental de tal manera que sea la paz sea una realidad y no mera retórica constitucional, pero además obliga a que el Estado se valga, únicamente, de medios pacíficos para lograr ese objetivo.

Justamente, con la finalidad de cumplir con ese deber, el gobierno colombiano inició las negociaciones con las FARC en el último trimestre del 2012 y se prolongaron hasta agosto de 2016. Una vez finalizado el proceso de negociación y cuando las partes llegaron a un arreglo, éste fue sometido a un plebiscito refrendatorio el 2 de octubre de 2016, en el cual se consultó al pueblo colombiano si apoyaba el acuerdo final para la terminación del conflicto y la construcción de una paz estable y duradera.

Los mecanismos democráticos de participación directa son herramientas idóneas para conocer la manera de pensar del pueblo. A través de ellos, se rompe la barrera de la representación política y los ciudadanos manifiestan su opinión en relación con el objeto de la consulta; sin embargo, los resultados que éstos arrojan no siempre son los más adecuados para la construcción de un Estado democrático. 
Por ejemplo, la Comisión Ejecutiva de Atención a Víctimas-CEAV del Gobierno Federal de los Estados Unidos Mexicanos-EUM en colaboración con la Universidad Nacional Autónoma de MéxicoUNAM realizó un estudio sobre la percepción popular de práctica de la tortura (EUM. CEAV. UNAM, 2016). Si bien se trata de un instrumento que carece de efectos jurídicos, en él se recabaron datos reveladores sobre su objeto de estudio y pone de relieve el riesgo que implica someter a la voluntad de las mayorías la obligación estatal de proteger y garantizar los derechos humanos.

En dicho análisis se documentó que sectores sustantivos de la población se mostraron a favor de la práctica de la tortura en contra de personas que cometieran el delito de secuestro (50.2\%) o el de violación (59.9\%), en contraste con el sector que se manifestó en desacuerdo con dicha práctica (28.2\% y $24.1 \%$, respectivamente).

La consulta al pueblo colombiano polarizó las opiniones respecto a la pacificación, pues aun cuando el sí ganó en las zonas más golpeadas por el conflicto armado, finalmente, el no fue la postura mayoritaria.

Los resultados de tal consulta popular fueron en contra del Acuerdo de Paz, el informe demuestra que las zonas con más víctimas respaldaron el acuerdo de paz en Colombia (Melgar, Zafra y Cucho, 2016), pues el 51,21\% respondió que no a la pregunta y sólo el $49,78 \%$ se mostró a favor de llegar a un arreglo.

Sobre este particular, cobra especial sentido el artículo 22 de la constitución colombiana (1991), pues al ser la paz un derecho humano no necesita legitimarse sobre la base del consenso mayoritario. Sobre este particular, el célebre jurista italiano, Luigi Ferrajoli, afirmó que el referéndum no era necesario para legitimar la paz colombiana y mucho menos es suficiente para deslegitimarla, de tal modo que, pese a los resultados negativos que arrojó, el proceso de pacificación no se veía comprometido (Martínez, 2016).

El autor italiano considera que el principio de la paz es tan importante como el principio de dignidad de la persona o los derechos a la igualdad, a la libertad o a la vida y, en la misma línea de pensamiento que pensadores como Hobbes y Kant, que la paz representa una precondición de la convivencia civil. 
Estas consideraciones traen consecuencias de gran calado, pues la interpretación de la Constitución colombiana (art. 22, 1991) conduce a una innegable inderogabilidad del derecho a la paz, la cual debe ser conseguida a cualquier costo, incluso contra la voluntad de la mayoría. Por ese motivo, Ferrajoli afirma que sobre la paz, igual que sobre cualquier otro derecho humano, no se vota ni se decide por mayorías; así, el resultado del plebiscito no reduce la obligación del Estado de garantizar la paz, sin importar qué tan aplastante sea la mayoría que se oponga a ello.

Justamente, en el Caso Gelman vs. Uruguay, la Corte Interamericana de Derechos Humanos sostuvo, que aun cuando una ley ha sido aprobada en el contexto de un régimen democrático e, incluso, respaldada y ratificada por la mayoría de los ciudadanos en dos ocasiones distintas, no la dota, ni automáticamente ni por sí sola, en una ley legítima a la luz del derecho internacional de los derechos humanos (CIDH, 2011). Esta afirmación se deriva de la existencia en Uruguay de una ley de caducidad (ley de amnistía) que condonaba la responsabilidad de las personas que habían cometido violaciones graves a derechos humanos en ese Estado, lo que perpetuaba el sufrimiento, la incertidumbre de las víctimas y, en última instancia, apostaba por la impunidad y por el olvido de las atrocidades cometidas por agentes del Estado y por particulares, en el marco de las dictaduras del cono sur en la década de los $70 \mathrm{y}$, particularmente, en el contexto de la denominada Operación Cóndor.

En consecuencia, la Corte Interamericana afirmó que en un régimen democrático la legitimación de ciertos hechos o actos está limitada:

[...] por las normas y obligaciones internacionales de protección de los derechos humanos reconocidos en tratados como la Convención Americana, de modo que la existencia de un verdadero régimen democrático está determinada por sus características tanto formales como sustanciales, por lo que, particularmente en casos de graves violaciones a las normas del Derecho Internacional de los Derechos, la protección de los derechos humanos constituye un límite infranqueable a la regla de mayorías, es decir, a la esfera de lo "susceptible de ser decidido" por parte de las mayoría" (CIDH, 2011, párr. 238). 
En la misma línea se ha pronunciado el mismo Tribunal interamericano en otros asuntos, como en el caso Almonacid Arellano y otros vs. Chile (CIDH, 2006). También diversos tribunales supremos y constitucionales del bloque latinoamericano y también organismos internacionales protectores de derechos humanos.

Entre ellos podemos hacer alusión al Consejo de Seguridad de la Organización de Naciones Unidas, el cual ha afirmado que existen normas y principios, reconocidos en el derecho internacional de los derechos humanos, en el derecho internacional humanitario, el derecho penal internacional y el derecho internacional de los refugiados, que orientan los actos de la institución (ONU, 2004). Estos principios también han sido acogidos por los ordenamientos jurídicos estatales de las más diversas tradiciones jurídicas, como el common law, la tradición romanista o el derecho islámico, por ejemplo.

El alcance de estos principios prohíbe a un Estado el poder garantizar la impunidad de las violaciones graves a derechos humanos a través de leyes de amnistías, aprobadas a través de procesos formalmente democráticos.

Por su parte, la Corte Suprema Argentina consideró que las leyes de amnistía son contrarias al espíritu de la $\mathrm{CADH}$ porque se orientan al olvido de graves violaciones de derechos humanos (Argentina. Corte Suprema de Justicia, 2005). Mientras en Chile, el Máximo Tribunal sostuvo que la soberanía interna del Estado [...] reconoce su límite en los derechos que emanan de la naturaleza humana; valores que son superiores a toda norma que puedan disponer las autoridades del Estado, incluido el propio Poder Constituyente, impidiendo sear desconocidos (Chile. Corte Suprema de Justicia, 2004).

En el caso de Nidia Sabalsagaray, la Suprema Corte de Justicia de Uruguay (2009) afirmó que:

En algunos casos, mediante una ley aprobada por una mayoría calificada, el Estado puede renunciar a penalizar ciertos hechos delictivos; empero, en el actual paradigma de los derechos humanos, el punto de énfasis del orden jurídico no se basa en la posición soberana de los Estados, sino en la persona en tanto titular, por su condición de tal, de los derechos esenciales que no pueden ser desconocidos, ni siquiera con base en el ejercicio del poder constituyente, ni originario ni derivado (Sentencia 365, 2009). 
Lo anterior demuestra como el consenso mayoritario no puede ser invocado como fuente de legitimidad cuando se está decidiendo sobre los derechos de las personas. Y es en este sentido que la paz no está sujeta a la voluntad de la mayoría para que su aprobación sea una realidad. La paz es una exigencia y una obligación constitucional y forma parte de la esfera de lo indecidible. Por esa razón no puede ser pasada por el tamiz de un referéndum o de un plebiscito, sujeto a la aprobación de la mayoría, pues esa opción equivale a desconocer su valor como un bien constitucionalmente protegido y la equipara a un objeto de negociaciones políticas, es decir, se debilita su carácter normativo en el sentido que autores como Ferrajoli (2011) y Habermas (2010) han referido.

Si bien es digno de reconocimiento el hecho de que el gobierno colombiano tomara en consideración la voluntad popular, pues en el fondo constituye un sano ejercicio democrático en cualquier, supeditar un derecho humano que también es una exigencia constitucional y -en el plano político y social- una precondición de la convivencia civil, corre el grave riesgo de no ser aprobado y arriesga la integridad de la sociedad en su conjunto.

\title{
Los acuerdos de Paz no constituyen per se una amnistía para los responsables de vulneración de Derechos Humanos
}

\begin{abstract}
Ahora bien, toda la argumentación anterior exige que hagamos una precisión conceptual entre los Acuerdos de Paz entre el Gobierno Colombiano y las FARC y las leyes de amnistía, proscritas por el ius commune interamericano con unanimidad. De acuerdo con la jurisprudencia de la CIDH (2011):
\end{abstract}

Las amnistías o figuras análogas han sido uno de los obstáculos alegados por algunos Estados para investigar y, en su caso, sancionar a los responsables de violaciones graves a los derechos humanos. Este Tribunal, la Comisión Interamericana de Derechos Humanos, los órganos de las Naciones Unidas y otros organismos universales y regionales de protección de los derechos humanos se han pronunciado sobre la incompatibilidad de las leyes de amnistía relativas a graves violaciones de derechos humanos con el derecho internacional y las obligaciones internacionales de los Estados (CIDH, 2011). 
Cuando un Estado establece una ley de amnistía, está apostando abiertamente al olvido y a la impunidad. En suma, apuesta a la denegación de justicia y a una paz artificial, pues las víctimas de violaciones a los derechos humanos no obtienen ninguna clase de reparación.

En este sentido, sería un error considerar que los Acuerdos de Paz constituyen una ley de amnistía, pues si bien renuncia a sancionar ciertas conductas (República de Colombia. Oficina del Alto Comisionado para la Paz. 2019):

(...) no es posible condonar la comisión de delitos de lesa humanidad, el genocidio, los graves crímenes de guerra, la toma de rehenes u otra privación grave de la libertad, la tortura, las ejecuciones extrajudiciales, la desaparición forzada, el acceso carnal violento (entre otras formas de violencia sexual), la sustracción de menores, el desplazamiento forzado, además del reclutamiento de menores conforme a los establecido en el Estatuto de Roma, estos delitos serán objeto del componente de justicia del Sistema Integral de Verdad, Justicia, Reparación y No Repetición (SIVJRNR) (Oficina del Alto Comisionado para la Paz, 2019).

La reparación de las víctimas es un aspecto central de los Acuerdos que se logra a través del esclarecimiento de la verdad.

Justamente, en las negociaciones de los Acuerdos, las partes se han acogido al artículo 6.5 del Protocolo II de los Convenios de Ginebra (Comité Internacional de la Cruz Roja-CICR, 1949). Dicho numeral dispone, a la letra, lo siguiente:

A la cesación de las hostilidades, las autoridades en el poder procurarán conceder la amnistía más amplia posible a las personas que hayan tomado parte en el conflicto armado o que se encuentren privadas de libertad, internadas o detenidas por motivos relacionados con el conflicto armado (CICR, 1949).

Sin embargo, la posibilidad de amnistiar ciertas conductas no es equivalente, conceptualmente, a la impunidad. Justamente, los Acuerdos establecen que la concesión de amnistías o indultos no exime del deber de contribuir al esclarecimiento de la verdad. 
Ferrajoli ha reconocido que este tipo de justicia es altamente excepcional y alternativa, pues el máximo objetivo es la verdad, por eso la pena privativa de la verdad se convierte en algo excepcional y la estigmatización pública por los horrores cometidos en la guerra, derivada de la confesión de los agresores que solicitan amnistía, se convierte en la verdadera pena (Ferrajoli, 2015).

De igual forma, la misma Corte Interamericana, mediante la sentencia del Caso Masacres de el Mozote y lugares aledaños vs. El Salvador (CIDH, 2012) y luego de referirse en diversos pronunciamientos al tema de las amnistías en su relación con la protección de derechos humanos y al deber del Estado de investigar, juzgar y sancionar sus graves vulneraciones, mediante la sentencia aludida, el Honorable Tribunal aduce la necesidad de realizar un análisis que proporcione criterios adecuados para un juicio de ponderación en contextos en los que se pudieran surgir tensiones entre las demandas de justicia con los requerimientos de una paz negociada en el marco de un conflicto armado no internacional.

Si bien existen algunos precedentes sobre leyes de amnistía, tal como lo arguye la Corte Interamericana, se debe tener en cuenta las particularidades, matices y énfasis propios, ya sea en cuanto al contexto que suscitó la aprobación de la Ley o el alcance de la misma. Desde el caso Barrios Altos vs. Perú (CIDH, 2001), hasta la sentencia de Masacres del Mozote (CIDH, 2012), todas las disposiciones que concedían amnistías tenían algo en común, ninguna de esas normas tenían como objeto principal poner fin, por la vía negociada a un conflicto armado. En cambio el caso de amnistía acaecido en El Salvador, deriva en un contexto diferente, lo que exhortó a la Corte a variar el análisis y calificación jurídica de los hechos, teniendo en cuenta normas propias del Derecho Internacional Humanitario, dado que la plataforma fáctica se desarrolló en el marco de un conflicto armado.

En este orden de ideas, se hace pertinente aclarar que en el Derecho Internacional no cuenta con un precepto o disposición que prohíba expresamente las amnistías. La única referencia al respecto, se puede encontrar en el artículo 6.5 del Protocolo Adicional II de las Convenciones de Ginebra (CICR, 1949). Al respecto el CICR ha 
comentado que su objeto “(...) es alentar un gesto de reconciliación que contribuya a restablecer el curso normal de la vida en un pueblo que ha estado dividido" (CICR, 1949).

Acorde con lo anterior, en la sentencia referida, la Corte ha señalado que:

Si bien las amnistías pueden ser permitidas como componente de la finalización de un conflicto armado no internacional, ellas tienen un límite cual es los crímenes de guerra y los crímenes de lesa humanidad, de modo tal que esos hechos no pueden quedar en la impunidad o el olvido (CIDH, 2012).

Estos límites también se encuentran en lo que algunos doctrinantes denominan como "fuentes implícitamente relacionadas a la amnistía” (Freeman, 2009).

La justicia transicional como garantía de la paz estable y duradera en el proceso de paz en Colombia

Aun, cuando la paz sea un derecho fundamental y un principio constitucional contra-mayoritario, no podemos obviar que la mayoría del pueblo colombiano se posicionó en contra de los acuerdos de paz.

Pareciera que, a nivel teórico, nos enfrentamos a un falso debate. En él, se colocan en extremos opuestos los derechos de las víctimas -en donde se incluye una suerte de pretensión sancionadora, homologable conceptualmente a la justicia, frente a los autores de los actos victimizantes- y el anhelo de alcanzar la paz.

Esta es la misma clase de falso debate que opera en discusiones como la del aborto y que ha sido resuelto de manera brillante por el Ministro Arturo Zaldívar, de la Suprema Corte de Justicia de México (arturozaldivar.com, 2011). Al respecto, el juez constitucional afirmó que:

Existe un falso debate entre quien está a favor de la vida y quien está a favor del aborto. Todos estamos a favor de la vida y nadie está a favor del aborto. El aborto es un drama humano para cualquier mujer (pp. 17-18). 
En un sentido paralelo, puede afirmarse que existe un falso debate entre los derechos de las víctimas del conflicto armado y la pretensión de justicia del pueblo colombiano. Todos estamos a favor de la justicia y nadie está a favor de la impunidad. La guerra ha dejado tras de sí una estela de dolor y violencia que debe ser mitigada y reparada; sin embargo, estas aspiraciones de justicia y reparación no tienen por qué conducir, necesariamente, a nuevas formas de violencia que, aun cuando puedan estar legitimadas por la ley (Ferrajolli, 2013), en nada abonan a alcanzar la paz, la efectiva reparación del daño y la reconciliación del pueblo colombiano.

Así, la renuncia condicionada de la persecución penal se justifica al ponderar la obligación de investigar, juzgar y en su caso sancionar, con el deber de prevenir futuras violaciones a los derechos humanos en la búsqueda de una paz estable y duradera (Sentencia C-579, 2013).

De acuerdo con la Corte Constitucional Colombiana:

Los mecanismos de suspensión condicional de ejecución de la pena, sanciones extrajudiciales, penas alternativas y las modalidades especiales de cumplimiento, no implican, por sí solos una sustitución de los pilares esenciales de la Carta, siempre que se encuentren orientados a satisfacer los derechos de las víctimas a la verdad, la justicia, la reparación y la no repetición (Sentencia C-579, 2013).

Justamente, las garantías de no repetición adquieren un rol protagónico en el contexto normativo de la justicia transicional. En efecto, éstas contienen el compromiso de adoptar medidas eficaces para evitar que se vuelvan a presentar violaciones a derechos humanos. Además, encierran un gran potencial de transformación de las relaciones sociales que tal vez sean las causas profundas de la violencia.

El arreglo institucional de la justicia de transición debe tener un enfoque holístico, que concilie la pretensión de justicia de la sociedad en su conjunto con el estado de cosas que vive el pueblo colombiano tras el fin del conflicto armado. Sobre este tenor, el Secretario General del Consejo de Seguridad de Naciones unidas (ONU, 2004) ha afirmado, mutatis mutandi, que no existe una fórmula general de la justicia de transicional 
En su informe sobre el Estado de derecho y la justicia de transición en las sociedades que sufren o han sufrido conflictos, el Secretario General (ONU, 2004) sostuvo:

La comunidad internacional debe concebir a esta clase de justicia como algo que va más allá de los juzgados y tribunales. En su planteamiento, se deben considerar y equilibrar diversos contenidos, entre ellos la rendición de cuentas, la búsqueda de verdad y reparación, la construcción y la preservación de una paz estable y duradera, así como de la democracia y del Estado de derecho (ONU. Consejo de Seguridad, 2004).

Además, aun cuando no sea determinante en términos de legitimidad la opinión de la mayoría con relación al modelo de justicia de transición para alcanzar la paz, el Secretario General del Consejo de Seguridad de Naciones Unidas (ONU, 2004) aconseja que se dé la oportunidad a las víctimas y a los grupos más afligidos por las consecuencias del conflicto armado para que viertan su opinión y decidan cuál es el punto de equilibrio adecuado.

Esto no implica desconocer el carácter contra-mayoritario de la paz al que ya hemos hecho referencia, sino que, únicamente, la voz de las víctimas debe ser escuchada con la finalidad de que la justicia transicional no se transforme en un nuevo proceso de victimización. En este tenor, son especialmente reveladores los datos del conteo final del referéndum, pues de acuerdo con los datos, con la salvedad de Antioquía, las zonas más afectadas por el conflicto se pronunciaron a favor del acuerdo de paz.

Estos datos respaldan el modelo de justicia diseñado por los Acuerdos, pues lo orientan como principios rectores el reconocimiento de las víctimas, no sólo en esa condición sino además como ciudadanos con derechos; el reconocimiento de responsabilidad frente a las víctimas del conflicto, pues en ningún caso se trata de un intercambio o negociación de inmunidades; la satisfacción de los derechos de las víctimas y su participación; el esclarecimiento de la verdad, la reparación integral de los daños causados; dotar a las víctimas de garantías de protección y seguridad personal que protejan su vida e integridad; establecer garantías de no repetición 
de tal forma que ningún colombiano vuelva a ser puesto en condición de víctima o en riesgo de serlo; y buscar la reconciliación del pueblo de Colombia para transitar por los caminos de la civilidad y la convivencia pacífica.

En este sentido, la justicia transicional es el instrumento idóneo para solucionar las tensiones.

[...] entre la justicia y la paz, entre los imperativos jurídicos de satisfacción de los derechos de las víctimas y las necesidades de lograr el cese de hostilidades. Para ello es necesario conseguir un delicado balance entre ponerle fin a las hostilidades y prevenir la vuelta a la violencia (paz negativa) y consolidar la paz mediante reformas estructurales y políticas incluyentes (paz positiva) (Sentencia C-579, 2013).

En efecto, en un proceso de búsqueda de una Paz estable y duradera, en un contexto de violencia sistemática y generalizada, se pueden implementar algunos mecanismos que conduzcan a un reconciliación nacional, pero que toman rumbos diversos y en consecuencia, tal y como lo asevera el Juez Diego García Sayán (CIDH, 2012b), se pueden presentar resultados que pueden "fijar los márgenes para el ejercicio de la ponderación de los intereses en el propósito de conjugar la investigación, sanción y reparación de graves violaciones a los derechos humanos, de un lado, con los de una salida negociada de un conflicto armado no internacional, por el otro. No hay solución universalmente aplicable a los dilemas que plantea esa tensión, pues ella depende de cada contexto aunque si hay lineamientos a tener en cuenta, tanto judiciales como no judiciales que se orienten simultáneamente en la búsqueda de la verdad, la justicia y la reparación".

Aunado a lo esbozado, se debe dejar claro que los derechos de las víctimas deben ser considerados como interdependientes para lograr los resultados esperados, con plena satisfacción de las mismas, conforme a los estándares internacionales. No obstante se reitera en la necesidad de una transformación real del contexto de violencia para impedir que se repitan los hechos de vulneración y que la adecuación de los acuerdos de paz se convierta en una fuente de impunidad con nefastas consecuencias. 
En el voto concurrente del Juez Diego García Sayán (CIDH, 2012b), se desarrolla el concepto de verdad y manifiesta que "además de lo esencial de la verdad judicial, propio del derecho a la justicia, ha llevado a muchas oportunidades a la puesta en funcionamiento de mecanismos como las comisiones de la verdad. El concepto de verdad no es unívoco y da lugar a diferentes interpretaciones".

En este orden de ideas, Boraine (2000), quien fuera vicepresidente de la Comisión de Verdad y Reconciliación de Sudáfrica conceptualizó la verdad en este tipo de situaciones en tres niveles:

a. la verdad factual, le da a la familia información concreta sobre el paradero de los restos mortales de la víctima o que pasó

b. la verdad personal, procura un efecto catártico en la persona que expresa o manifiesta esa verdad.

c. la verdad social, es la que la sociedad adopta a través del diálogo y el debate. Juegan un papel importante medidas como la apertura de la documentación en manos del Estado, la revisión de los textos escolares y la construcción de museos o memoriales de lo ocurrido.

En lo concerniente al derecho de justicia de las víctimas, se hace énfasis en la obligación del Estado de investigar, juzgar y sancionar las graves violaciones a los derechos humanos. Entendiendo que la investigación se debe realizar bajo el estándar de la debida diligencia y que se concibe como una obligación de medio y no de resultado, que hace parte del deber de garantía y en tratándose de vulneración de Derechos, se debe tener como una obligación de naturaleza continuada, es decir, de ejecución permanente hasta el restablecimiento del derecho.

El otro criterio a tener en cuenta es la manera como el Estado pretende juzgar a los responsables, garantizando los recursos adecuados y efectivos en ejercicio del acceso a la justicia para las víctimas del conflicto armado, sin desconocer el equilibrio que debe existir entre una justicia penal y una paz negociada.

Para lograr dicha armonía, en aras de resolver el conflicto existente entre estos dos derechos, se hace necesario recurrir a un test de proporcionalidad en el marco de la justicia transicional. 
En éste sentido, "los Estados deben ponderar en este tipo de circunstancias el efecto de la justicia penal tanto sobre los derechos de las víctimas como sobre la necesidad de terminar el conflicto. Pero, para ser válidas en el derecho internacional, tendrían que atenerse a ciertos estándares básicos orientados a lo que puede procesarse y concretarse de varias formas, incluyendo el papel de la verdad y la reparación" [...] "Entendiendo esta obligación estatal desde tres elementos básicos:

a. la actividad orientada a investigar y esclarecer los hechos

b. la identificación de las responsabilidades individuales

c. la aplicación de sanciones proporcionales a la gravedad de las violaciones" (CIDH, 2012b).

En cuanto al deber de sancionar a los responsables, se debe hacer especial alusión, que en el Derecho internacional no existe una norma que determine expresamente o establezca una sanción para los responsables de crímenes que atentan contra los derechos humanos, por lo cual, se hace procedente acudir a penas alternativas para lograr recuperar la confianza en la sociedad.

Como colofón se hará referencia a la reparación integral como elemento de la justicia transicional, establecido con el propósito de sentar bases sólidas que impidan la reiteración de los hechos violatorios de derechos.

No obstante lo anterior, el componente reparatorio tiene sus propias dificultades y hasta imposibilidades, cuando se trata de casos masivos y extendidos de atropellos a los derechos de las personas (De Greiff, 2005). Tal y como lo establecido la CIDH (2016), "si bien en principio las medidas de reparación tienen una titularidad individual, dicha situación puede variar cuando los Estados se ven forzados a reparar masivamente a numerosas víctimas, excediéndose ampliamente las capacidades y posibilidades de los tribunales internos. Los programas administrativos de reparación se presentan entonces como una manera legítima de hacer frente a la obligación de posibilitar la reparación. En adición, frente a contextos de violaciones masivas y graves a derechos humanos, esas medidas de reparación deben concebirse junto con otras medidas 
de verdad y justicia, y cumplir con ciertos requisitos relacionados, entre otros, con su legitimidad -en especial, a partir de la consulta y participación de las víctimas-, en aspectos como los siguientes: su adopción de buena fe; el nivel de inclusión social que permiten; la razonabilidad y proporcionalidad de las medidas pecuniarias; el tipo de razones que se esgrimen para hacer reparaciones por grupo familiar y no en forma individual; los criterios de distribución entre miembros de una familia, y parámetros para una justa distribución que tenga en cuenta la posición de las mujeres entre los miembros de la familia" (CIDH, 2016).

Sin embargo, a pesar de las dificultades el Estado es el llamado a considerar la paz como un derecho humano y a la vez, una obligación alcanzarla sin desconocer los derechos de las víctimas.

\section{Retos y limitaciones de la justicia transicional en Colombia}

Si bien la justicia transicional es un arreglo político-jurídico necesario para superar la situación estructural y sistemática de violación de Derechos Humanos, también es cierto que Colombia no se está estrenando en este ámbito. De sus experiencias previas podemos resaltar los retos más importantes a los que se enfrenta este sistema de justicia para lograr materializar la intención de construir una paz estable y duradera. Los principales retos están asociados a la tensión entre el grado de satisfacción del derechos de las víctimas y este derecho contra-mayoritario de la paz.

Una de las experiencias más significativas está cerca de cumplir quince años: La masacre de Bojayá ocurrida el 2 de mayo de 2002 con ocasión a los combates entre el Frente 58 de las FARC-EP y el Bloque Elmer Cárdenas de las Autodefensas Unidas de Colombia (AUC) en el municipio de Bojayá, Medio Atrato (Chocó, Colombia).

Esta tragedia ha sido un símbolo cuya finalidad ha mutado a través del tiempo. Inmediatamente ocurrida la masacre, Bojayá se convirtió en el motivo para fortalecer a las Fuerzas Armadas y procurar la derrota militar de la guerrilla (Grupo de Memoria Histórica-GMH, 2010, p. 249). Hoy en día, avocados a la implementación de un acuerdo político para la terminación del conflicto armado, Bojayá se ha convertido en un símbolo del perdón y de 
cómo es que en Colombia se está haciendo posible lo imposible: la construcción de una paz estable y duradera (Santos, 2016).

En medio de los usos de la tragedia se encuentra una comunidad que busca poner en relieve las causas estructurales que dieron lugar a la grave situación de vulneración de derechos humanos en la zona: el abandono y la histórica discriminación de comunidades afrodescendientes e indígenas (GMH, 2010, p. 236).

En ese sentido, es valioso recordar que los hechos que rodearon la masacre de Bojayá y la actividad desplegada por el Estado Colombiano para atender a las víctimas están enmarcados dentro del contexto de la implementación de varios regímenes de justicia transicional los cuales, han merecido múltiples pronunciamientos por parte de la Comisión Interamericana de Derechos Humanos quien ha reconocido la dificultad de adoptar medidas que permitan superar, de manera definitiva, las condiciones que han dado lugar a eventos como el de Bojayá, en ese sentido, la CIDH ha reiterado en múltiples ocasiones que (...) la violencia derivada de la falta de una desarticulación efectiva y completa de las estructuras armadas de grupos paramilitares, continúa impactando severamente los derechos de las y los habitantes en Colombia (CIDH, 2013, p.17).

En la actualidad, este esfuerzo por superar las violaciones de derechos humanos provocadas por la confrontación armada está contenida en el "Acuerdo final para la terminación del conflicto y la construcción de una paz estable y duradera" firmado entre el Estado Colombiano y las FARC-EP y cuya refrendación se realizó, por vía del Congreso de la República, el 30 de noviembre de 2016.

Quince años después, los reclamos sobre cómo el Estado colombiano ha cumplido con sus obligaciones internacionales recaen, como se anticipó, sobre el nivel de satisfacción del derecho de las víctimas y, en especial, el derecho a la verdad. Al respecto, el Informe del Centro Nacional de Memoria Histórica (2010), al respecto, disponen: “(...) las investigaciones no fueron iniciadas contra todos los actores relacionados con los hechos, específicamente en lo que atañe a los integrantes del Bloque Élmer Cárdenas y algunos miembros de las Fuerzas Militares relacionados con los sucesos posteriores al 7 de mayo y su presunta omisión o colaboración 
frente al paso de las pangas de los paramilitares en abril de 2002" (GMH, 2010, p. 231).

En ese contexto, queda claro que los reclamos se concentran en exaltar las falencias del Estado al no involucrar con el mismo rigor en las investigaciones a los paramilitares y a los agentes del Estado. Lo anterior, debido a que los diferentes mecanismos de justicia transicional implementados han privilegiado la investigación, juzgamiento y sanción de responsables directos de las graves violaciones a los derechos humanos y al Derecho Internacional Humanitario, en este caso, los miembros de las FARC que lanzaron un artefacto explosivo contra la Iglesia donde se refugiaba la población civil de Bojayá durante los combates entre paramilitares y guerrilleros.

$\mathrm{Al}$ respecto, habrá que señalar que el Acuerdo final para la terminación del conflicto y la construcción de una paz estable y duradera consagra el Sistema Integral de Verdad, Justicia, Reparación y No Repetición como el componente de justicia y, en él, la verdad juega un rol determinante.

Sin embargo, en la actualidad no hay avances significativos en las líneas de investigación que relacionan a los agentes del Estado con esta tragedia y, por ende, la relación entre la contribución voluntaria de cada persona a la construcción de la verdad y el tratamiento especial que en materia punitiva prevé el acuerdo no es un incentivo para quienes, desde el Estado, facilitaron o tuvieron alguna relación con la masacre (GMH, 2010).

Así mismo, aún no hay claridad sobre la forma en la que se concretará la aplicación diferenciada, otorgando un tratamiento equitativo, equilibrado, simultáneo y simétrico de las Fuerzas Armadas $\mathrm{y}$, con ello, los juicios sobre la vocación de justicia o la verosimilitud de los procedimientos que se adelanten en el componente de justicia del acuerdo resultan apresurados.

Sin embargo, hay elementos del acuerdo que nos permiten sostener que se privilegia la investigación y sanción de la responsabilidad directa en perjuicio de la responsabilidad derivada de la posición de garante, lo cual, compromete seriamente la posibilidad de esclarecer el rol de los agentes del Estado en esta masacre. So- 
bre el particular, el acuerdo consagra: "En ningún caso la responsabilidad del mando podrá fundarse exclusivamente en el rango, la jerarquía o el ámbito de jurisdicción. La responsabilidad de los miembros de la fuerza pública por los actos de sus subordinados deberá fundarse en el control efectivo de la respectiva conducta, en el conocimiento basado en la información a su disposición antes, durante y después de la realización de la respectiva conducta, así como en los medios a su alcance para prevenir, y de haber ocurrido, promover las investigaciones procedentes" (República de Colombia. FARC-EP. Acuerdo Final, 2016, Punto 44).

\section{Conclusiones}

Estas breves consideraciones dejan entrever que no son halagüeñas las posibilidades de esclarecer la participación de los agentes del Estado en la masacre, en especial, cuando lo que se ha defendido es un discurso que atribuye directa y exclusivamente la responsabilidad de lo ocurrido a las FARC-EP, tal y como quedó en evidencia durante el discurso que diera el presidente Juan Manuel Santos al recibir el Premio Nobel de Paz quien destacó a Bojayá como una muestra de la barbarie pero, sobre todo, de la reconciliación entre las FARC-EP y la sociedad civil representada por Leyner Palacios como sobreviviente de este atroz hecho.

El derecho a la paz reconocido por el artículo 22 de la Constitución Colombiana (1991) exige, por su propia naturaleza trascender al plano de la realidad. Esta exigencia se agrava cuando tomamos en consideración que el mismo precepto reconoce que la paz, además de un derecho, es un deber de cumplimiento obligatorio. Esta situación normativa convierte al derecho a la paz en uno de carácter contra-mayoritario. Además, al ser un deber de cumplimiento obligatorio, constriñe al Estado a adoptar todas las medidas que sean necesarias para que la paz sea una realidad y no una simple promesa sobre el papel.

Queda descartada la posibilidad de comparar los Acuerdos de Paz con una amnistía en los términos que la jurisprudencia comparada e interamericana ha proscrito rotundamente. El perdón que 
ofrecen los Acuerdos no encuentra sus cimientos en el olvido y en la impunidad, sino en la efectiva reparación de los daños generados a las víctimas y en la reconciliación del pueblo colombiano. Cuando un Estado reconoce un derecho fundamental en su Constitución, también reconoce su obligación de protegerlo y garantizarlo, de tal modo que las promesas constitucionales trasciendan al ámbito material y se vean reflejadas en la vida de cada una de las personas bajo su jurisdicción. Esta es una premisa reconocida por la jurisprudencia interamericana (CIDH, 1988) y por la teoría general del derecho (Ferrajoli, 2009), de tal modo que la efectividad del derecho -y de los derechos humanos reconocidos en las constituciones y en los tratados internacionales- depende, en buena medida, de la efectividad de los mecanismos diseñados para hacerlos efectivos y eficaces.

De otro lado, otra de las objeciones contantes formuladas a la implementación de estos procesos de justicia transicional tiene que ver con la reparación de las víctimas. Al respecto, en el caso de Bojayá, las medidas de reparación adoptadas han desarrollado lo provisto en la Ley 1448 (2011) que, respecto de los daños materiales, encuentra su reglamentación en el decreto 1377 (2014) impiden el reconocimiento y pago de una indemnización administrativa que exceda los 40 salarios mínimos legales mensuales vigentes por persona y sin importar si en él confluyen múltiples violaciones o si una misma violación afectó diferentes bienes constitucionales. Así mismo, se ha podido verificar que las medidas de satisfacción implementadas han centrado su atención en el componente de mitigación del dolor o las gestiones emocionales de la población afectada (Buchely, 2016), dejando de lado el objetivo de proporcionar bienestar de sus habitantes.

Por su parte, la Corte Interamericana, en relación con los daños materiales ha previsto dos medidas de reparación: (i) La restitución y, (ii) la indemnización. La primera en los casos que es posible el restablecimiento de las cosas al estado anterior a los eventos dañosos y, cuando no sea posible, ha previsto el reconocimiento y pago de una justa indemnización de la cual, ha definido sus componentes así: (i) daño emergente, (ii) pérdida de ingreso y (iii) el daño moral. 
Estos, a su vez, tienen como único límite el carácter compensatorio de la indemnización (CIDH, 2004, Párr. 189).

Se demuestra que la paz es un valor superior, pues sin paz no es posible aspirar a la justicia, mucho menos a la democracia y a la garantía de los derechos de las víctimas y los derechos fundamentales de la población colombiana.

En ese contexto, los retos más importantes se reflejarán en la forma en la que se reconstruya la verdad de lo ocurrido involucrando la participación de todos los actores del conflicto y, además, de lograr una reparación que garantice un equilibrio entre la reparación y sostenibilidad fiscal del acuerdo.

\section{REFERENCIAS}

Ander-Egg, E. (2014). Como elaborar monografías, artículos científicos y otros textos. Santa Fe: Homo sapiens.

Arias, F. (2006). El Proyecto de Investigación. Introducción a la metodología científica. $6^{\mathrm{a}} \mathrm{Ed}$. Caracas: Episteme.

arturozaldivar.com. (28 de septiembre de 2011). Voto particular que formula el Ministro Arturo Zaldivar Lelo de Larrea en relación con las acciones de inconstitucionalidad 11/2009 y 62/2009. [Online]. Recuperado de https://arturozaldivar.com/sites/default/files/votos/pdf/Voto\%20particular\%20AI\%2011-2009\%20y\%2062-2009.pdf

Balcázar, P., Gonzalez, N., Gurrola, G. y Moysen, A. (2015). Investigación cualitativa. [3. Ed.]. México, D.F.: Universidad Autónoma del Estado de México Recuperado de http://hdl. handle.net/20.500.11799/21589

Boraine, A. (2000). A Country Unmasked: Inside South Afroca's Truth and Reconciliation Comission. Oxford and New York: Oxford University Press.

Buchely, L. (2016). Estado Empático Y Ciudadanía Precaria: Reflexiones en torno al caso emblemático de Bellavista (Bojayá-Colombia). Revista da Faculdade de Direito UFPR, 6(1), 211-230. http://dx.doi.org/10.5380/rfdufpr. v62i1.50742 
CICR. (1949). Convenios de Ginebra. [Artículo 65]. Recuperado de https://www.icrc.org/es/document/los-convenios-de-ginebra-de-1949-y-sus-protocolos-adicionales

CIDH. (22 de noviembre de 2016). Caso Yarce y otras vs. Colombia. Excepciones Preliminares, Fondo, Reparaciones y costas. [Serie C No. 325]. Recuperado de http://www.corteidh. or.cr/docs/casos/articulos/seriec_325_esp.pdf

CIDH. (2013). Informe de país Colombia: Verdad, justicia y reparación. [OEA/Serie L/V/II. Doc. 49/13]. Washington D.C.: Organización de Estados Americanos.

CIDH. (25 de octubre de 2012). Caso Masacres de El Mozote y Lugares Aledaños vs. El Salvador. [Serie C No. 252]. Recuperado de http://corteidh.or.cr/docs/casos/articulos/seriec_252_esp.pdf

CIDH. (2012b). Voto concurrente del juez diego garcia-sayán. [Online]. Recuperado de http://corteidh.or.cr/docs/casos/votos/ vsc_sayan_252_esp.doc

CIDH. (24 de febrero de 2011). Caso Gelman Vs. Uruguay. Fondo y Reparaciones. [Serie C No. 221]. Recuperado de http:// www.corteidh.or.cr/docs/casos/articulos/seriec_221_esp1. pdf

CIDH. (2010). Voto razonado del Juez ad hoc Eduardo Ferrer MacGregor Poisot en relación con la sentencia de la Corte Interamericana de Derechos Humanos en el Caso Cabrera García y Montiel Flores vs. México. [Online]. Recuperado de http://www.corteidh.or.cr/docs/casos/votos/vsc_ferrer_220_esp.doc

CIDH. (26 de septiembre de 2006). Caso Almonacid Arellano y otros vs. Chile. Excepciones Preliminares, Fondo, Reparaciones y costas. [Serie C No. 154]. Recuperado de http:// www.corteidh.or.cr/docs/casos/articulos/seriec_154_esp. pdf

CIDH. (8 de julio de 2004). Caso de los Hermanos Gómez Paquiyauri Vs Perú. Sentencia de Fondo, Reparaciones y Costas. [Serie C No. 110]. Recuperado de http://www.corteidh. or.cr/docs/casos/articulos/seriec_110_esp.pdf 
CIDH. (30 de noviembre de 2001). Sentencia Caso Barrios Altos vs. Perú. [Serie C No. 75]. Recuperado de http://www. corteidh.or.cr/docs/casos/articulos/Seriec_87_esp.pdf

CIDH. (29 de julio de 1988). Velásquez Rodríguez Vs. Honduras. Fondo. [Serie C No. 4]. Recuperado de http://www.corteidh.or.cr/docs/casos/articulos/seriec_04_esp.pdf

De Greiff, P. (2005). Repairing the Past: Confronting the Legacies of Slavery, Genocide, \& Caste. Connecticut: Yale University.

Estraño, J. (2009). La Técnica de la Investigación Jurídica Dogmática (II). [Online]. Recuperado de https://entornoempresarial.com/la-tecnica-de-la-investigacion-juridicadogmatica-ii/

EUM. UNAM. CEAV. (2016). Documento Ejecutivo sobre los resultados del Diagnóstico Nacional de la Percepción de la Población sobre la Práctica de la Tortura. [Online]. Obtenido de http://historico.juridicas.unam.mx/novedades/ documento-tortura/documento-ejecutivo-10032016.pdf

Ferrajoli, L. (2015). Democracia y garantismo. Madrid: Editorial Trotta.

Ferrajoli, L. (2011). Principia iuris. Madrid: Editorial Trotta.

Ferrajoli, L. (2009). Los fundamentos de los derechos fundamentales. Madrid: Editorial Trotta.

Freeman, M. (2009). Necessary Evils: Amnesties and the search for justice. Cambridge: Cambridge University Press.

Habermas, J. (2010). Facticidad y validez. Madrid: Editorial Trotta.

Martínez, H. (2012). Metodología de la investigación con enfoque en competencias. México, D.F.: Cengage learning.

Martínez, M. (Octubre 25, 2016). El plebiscito no era necesario para legitimar la paz, y menos para deslegitimarla. Semana. Obtenido de http://www.semana.com/nacion/articulo/jurista-italiano-luigi-ferrajoli-dice-que-plebiscitono-era-necesario/501096 
Melgar, L., Zafra, M. y Cucho, A. (Octubre 2, 2016). Los gráficos que demuestran que las zonas con más víctimas respaldaron el acuerdo de paz en Colombia. Univisión Noticias. Disponible en http://www.univision.com/noticias/ proceso-de-paz/los-graficos-que-demuestran-que-laszonas-con-mas-victimas-respaldaron-el-acuerdo-de-pazen-colombia.

ONU. Consejo de Seguridad. (2004). Informe del Secretario General al Consejo de Seguridad de Naciones Unidas. El Estado de derecho y la justicia de transición en las sociedades que sufren o han sufrido conflictos. [U.N. Doc. S/2004/616]. Recuperado de https://undocs. org/S/2004/616

República de Colombia. Oficina del Alto Comisionado para la Paz. (noviembre 5, 2019). P\&R: Sistema integral de Verdad, Justicia, Reparación y no Repetición. [Online]. Obtenido de http://www.altocomisionadoparalapaz.gov.co/ procesos-y-conversaciones/proceso-de-paz-con-las-farcep/Paginas/PR-Sistema-integral-de-Verdad-Justicia-Reparacion-y-no-Repeticion.aspx

República de Colombia. Asamblea Nacional Constituyente. (1991). Constitución política de Colombia. [Artículo 22]. Gaceta Oficial (116).

República de Colombia. Comisión Nacional de Reparación y Reconciliación. GMH (2010). Bojayá: la guerra sin límites. Bogotá D.C.: Taurus.

República de Colombia. Corte Constitucional. (10 de junio de 2011). Por la cual se dictan medidas de atención, asistencia y reparación integral a las víctimas del conflicto armado interno y se dictan otras disposiciones. [Ley 1448]. Diario Oficial: 48.096.

República de Colombia. Corte Constitucional. Sala de Revisión de tutelas (22 de enero de 1992). Exp. T-399. [Sentencia ST008/92]. Magistrado Ponente: Fabio Morón Díaz. 
República de Colombia. Corte Constitucional. (28 de agosto de 2013). Exp. D-9499. [Sentencia C-579/13]. Magistrado Ponente: Jorge Ignacio Pretelt Chalju.

República de Colombia. Presidencia de la República. (22 de julio de 2014). Por el cual se reglamenta parcialmente el artículo 132 de la Ley 1448 de 2011 y se modifica elartículo 159 del Decreto 4800 de 2011 en lo concerniente a la medida de indemnización a las víctimas de desplazamiento forzado, se regulan algunos aspectos de retomo y reubicación y se dictan otras disposiciones. [Decreto 1377]. DO: 49.220.

República de Argentina. Corte Suprema de Justicia de la Nación. (14 de junio de 2005). Caso Simón, Julio Héctor y otros s/privación ilegítima de la libertad, etc. (Poblete). Causa 17.768. [S. 1767. XXXVIII]. Recuperado de http://www. saij.gob.ar/descarga-archivo?guid=rstuvwfa-llos-compuest-o05000115pdf\&name $=05000115$.pdf

República de Chile. Corte Suprema de Justicia de la Nación. (17 de noviembre de 2004). Decisión del Pleno respecto de la instancia que verá la aplicación de la Ley de Amnistía en el caso del secuestro del mirista Miguel Ángel Sandoval. [Rol No. 517-2004, Caso 2477]. Recuperado de http:// www.corteidh.or.cr

República de Colombia. Farc-Ep. (24 de noviembre de 2016). Acuerdo Final para la Terminación del Conflicto y la Construcción de una Paz Estable y Duradera. [Acuerdo Final 24.11.2016]. Disponible en https://www.mesadeconversaciones.com.co/sites/default/files/24-1480106030.111480106030.2016nuevoacuerdofinal-1480106030.pdf

República de Colombia. Oficina del Alto Comisionado para la Paz. (noviembre 5, 2019). P\&R: Sistema integral de Verdad, Justicia, Reparación y no Repetición. [Online]. Disponible en http://www.altocomisionadoparalapaz.gov.co/procesosy-conversaciones/proceso-de-paz-con-las-farc-ep/Paginas/ PR-Sistema-integral-de-Verdad-Justicia-Reparacion-yno-Repeticion.aspx 
República Oriental del Uruguay. Suprema Corte de Justicia. (19 de octubre de 2009). Caso "Sabalsagaray Curutchet Blanca Stela - Denuncia de Excepción de Inconstitucionalidad". [Sentencia 365]. Recuperado de https://www. gub.uy/secretaria-derechos-humanos-pasado-reciente/ sites/secretaria-derechos-humanos-pasado-reciente/files/documentos/publicaciones/SABALSAGARAY\%20 CURUTCHET\%2C\%20Nibia\%20Gloria.pdf

Sabino, C. (1996). El proceso de investigación. Caracas: Panapo.

Santos, J. M. (2016). Minuto a Minuto: Juan Manuel Santos recibe el premio Nobel de Paz. Semana. [Video]. Recuperado de https://www.semana.com/nacion/multimedia/juan-manuel-santos-recibe-el-premio-nobel-de-paz-2016/508768

U.S. Supreme Court. SCOTUS. (1857). Dred Scott v. Sandford. [60 U.S. (19 How.) 393]. Available from https://supreme. justia.com/cases/federal/us/60/393/

U.S. Supreme Court. SCOTUS. (1896). Plessy v. Fergusson, [163 U.S. 537]. Available from https://supreme.justia.com/cases/federal/us/163/537/

U.S. Supreme Court. SCOTUS. (1954). Brown v. Board of Education. [347 U.S. 483]. Available from https://supreme.justia.com/cases/federal/us/163/537/ 
Berónica Narváez Mercado es Doctorante de la Universidad Libre de Bogotá (Colombia) con Magister en Administración y Derecho Empresarial de la Universidad Libre de San José (Costa Rica), Abogada de la Universidad Libre (Bogotá, Colombia) y Directora del Proyecto de Investigación de Colciencias Consuma Caribe. Directora del Centro de Investigación Socio jurídica de CECAR. https://orcid.org/0000-0003-4161-9275

Namiko Matzumoto Benitez es Doctora en Derecho y Magister en Psicología Jurídica y Criminología del Instituto Universitario de Puebla (México). Licenciada en Derecho de la Universidad Veracruzana (México). Presidenta de la Comisión Estatal de Derechos Humanos de Veracruz. Investigadora del Instituto de Investigaciones Jurídicas de la Universidad Veracruzana (México). https:// orcid.org/0000-0003-3199-0273

Luz Elena Mira-Olano es Doctora en Ciencias Jurídicas de la Universidad Católica (Argentina) con Magister en Derechos Humanos y Democracia. Especialista en Derecho Penal y Abogada. Investigadora categoría Junior de Colciencias. Docente Universitaria del Tecnológico de Antioquia I.U. (Colombia). https://orcid. org/0000-0001-8686-0519

Alejando Zúñiga-Bolívar es Magister en Derecho de la Universidad Externado, abogado de la Universidad ICESI, Docente Investigador en la Corporación Universitaria de Colombia y Director de AZB abogados. https://orcid.org/0000-0003-3382-2927 